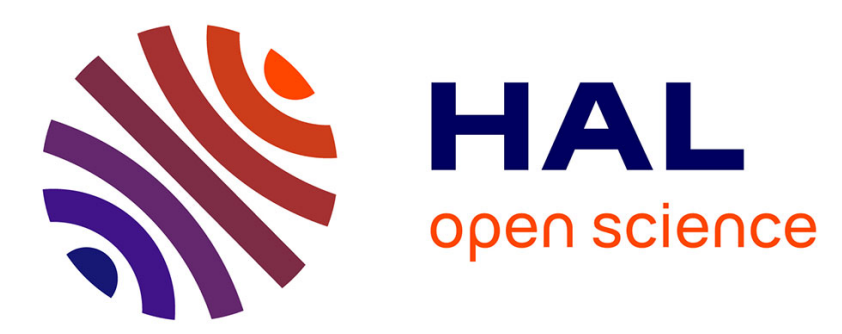

\title{
Development of a new family of monolithic calcium (pyro)phosphate glasses by soft chemistry
}

Jérémy Soulié, Pierre Gras, Olivier Marsan, Danielle Laurencin, Christian Rey, Christèle Combes

\section{- To cite this version:}

Jérémy Soulié, Pierre Gras, Olivier Marsan, Danielle Laurencin, Christian Rey, et al.. Development of a new family of monolithic calcium (pyro)phosphate glasses by soft chemistry. Acta Biomaterialia, 2016, 41, pp.320-327. 10.1016/j.actbio.2016.05.030 . hal-01361844

\section{HAL Id: hal-01361844 \\ https://hal.science/hal-01361844}

Submitted on 23 Oct 2017

HAL is a multi-disciplinary open access archive for the deposit and dissemination of scientific research documents, whether they are published or not. The documents may come from teaching and research institutions in France or abroad, or from public or private research centers.
L'archive ouverte pluridisciplinaire $\mathbf{H A L}$, est destinée au dépôt et à la diffusion de documents scientifiques de niveau recherche, publiés ou non, émanant des établissements d'enseignement et de recherche français ou étrangers, des laboratoires publics ou privés. 


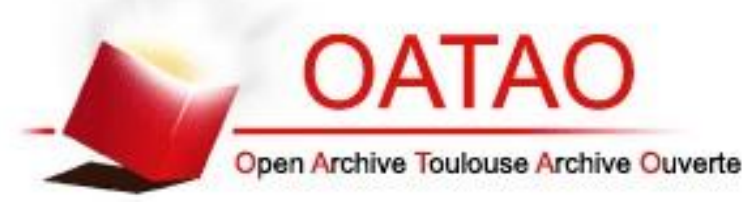

\section{Open Archive TOULOUSE Archive Ouverte (OATAO)}

OATAO is an open access repository that collects the work of Toulouse researchers and makes it freely available over the web where possible.

This is an author-deposited version published in : http://oatao.univ-toulouse.fr/ Eprints ID : 18208

To link to this article : DOI:10.1016/j.actbio.2016.05.030

URL : https://doi.org/10.1016/j.actbio.2016.05.030

To cite this version : Soulié, Jérémy and Gras, Pierre and Marsan, Olivier and Laurencin, Danielle and Rey, Christian and Combes, Christèle Development of a new family of monolithic calcium (pyro)phosphate glasses by soft chemistry. (2016) Acta

Biomaterialia, vol. 41. pp. 320-327. ISSN 1742-7061

Any correspondence concerning this service should be sent to the repository administrator: staff-oatao@ listes-diff.inp-toulouse.fr 


\title{
Development of a new family of monolithic calcium (pyro)phosphate glasses by soft chemistry
}

\author{
Jérémy Soulié $^{\mathrm{a}, *}$, Pierre Gras $^{\mathrm{a}}$, Olivier Marsan ${ }^{\mathrm{a}}$, Danielle Laurencin ${ }^{\mathrm{b}}$, Christian Rey ${ }^{\mathrm{a}}$, Christèle Combes ${ }^{\mathrm{a}}$ \\ ${ }^{a}$ CIRIMAT, UMR 5085 INPT-CNRS-UPS, Université de Toulouse, ENSIACET, 4 Allée Emile Monso, 31030 Toulouse, France \\ ${ }^{\mathrm{b}}$ ICGM, UMR5253, CNRS-UM-ENSCM, Place Eugène Bataillon, 34095 Montpellier, France
}

\begin{abstract}
A B S T R A C T
The development of bioactive phosphate-based glasses is essential in biomaterials science, and especially for bone substitution applications. In this context, the preparation of amorphous calcium-phosphorus hydroxide/oxide monoliths at low temperature is a key challenge for being able to develop novel hybrid materials for these applications. We herein report for the first time the synthesis and physical chemical characterisation of a novel family of pyrophosphate-based glasses (with the formula: $\left\{\left[\left(\mathrm{Ca}^{2+}\right)_{1-\mathrm{x}}\left(\mathrm{H}^{+}\right]\right.\right.$ $\left.\left.\left.\left.\mathrm{K}^{+}\right)_{2 \mathrm{x}}\right]_{2}\left[\left(\mathrm{P}_{2} \mathrm{O}_{7}^{4-}\right)_{1-\mathrm{y}}\left(\mathrm{PO}_{4}^{3-}\right)_{4 \mathrm{y} / 3}\right]\right\} \mathrm{n}\left(\mathrm{H}_{2} \mathrm{O}\right)\right)$, which were prepared by soft chemistry using low temperatures $\left(\mathrm{T}<70^{\circ} \mathrm{C}\right)$ and water as a solvent. The effect of the initial $\mathrm{Ca} /$ Pyrophosphate ratio on the structure and morphology of these pyrophosphate glasses was investigated in detail. Depending on this ratio, a glass (mixed calcium pyro- and orthophosphate) or a glass-ceramic $\left(\mathrm{Ca}_{10} \mathrm{~K}_{4}\left(\mathrm{P}_{2} \mathrm{O}_{7}\right)_{6} \cdot 9 \mathrm{H}_{2} \mathrm{O}\right.$ crystals embedded in the amorphous phase) was obtained. The proportion of the crystalline phase increased with an increase in the $\mathrm{Ca} /$ Pyrophosphate ratio in the batch solution. As expected for a glass, the formation of the glassy material was demonstrated not to be thermodynamically but rather kinetically driven, and the washing step was found to be crucial to prevent crystallisation. The stability of the amorphous phase was discussed considering the structural degrees of freedom of pyrophosphate entities, ionic strength of the initial solution and the inhibitory effect of orthophosphate ions. Overall, this new strategy of preparation of monolithic calcium-(pyro)phosphate based glasses using soft chemistry in water is highly promising in view of preparing new functional organic-inorganic hybrids for bone substitution applications.
\end{abstract}

\section{Statement of Significance}

Phosphate-based glasses have gradually emerged as a potential alternative to silicate bioactive glasses in order to induce different biological mechanisms of degradation. The synthesis of such monolithic glasses at low temperature is a key step to allow new inorganic glass compositions to be reached and hybrid materials to be prepared. Although sol-gel and coacervate methods (respectively orthophosphate and metaphosphate precursors) have already been described to prepare such glasses, the use of toxic solvents and/or the final temperature treatment associated to these processes could limit the use of these materials for biomedical applications and/or the further development of hybrids. It is shown here that pyrophosphate precursors are an alternative strategy to obtain monolithic calcium (pyro)phosphate glasses under soft conditions (water solvent, $70^{\circ} \mathrm{C}$ ).

\section{Introduction}

Since their discovery by L.L. Hench in the 1960s [1], bioactive glasses have been extensively studied as biomaterials for bone substitution. Bioglass ${ }^{\circledR}$ is currently commercialised for orthopaedics and dental applications and has become a reference material to

\footnotetext{
* Corresponding author.

E-mail address: jeremy.soulie@ensiacet.fr (J. Soulié).
}

evaluate the performance of new silicate-based bioactive glasses. Hench developed silica-based glasses (Fig. 1-a), which were first prepared as most glasses by fusion, and initially composed of four kinds of oxides: $\mathrm{SiO}_{2}-\mathrm{CaO}-\mathrm{P}_{2} \mathrm{O}_{5}-\mathrm{Na}_{2} \mathrm{O}$. The use of the sol-gel route (soft chemistry) was the second important step in the development of bioactive glasses. The associated low temperature has allowed new inorganic glass compositions $\left(\mathrm{SiO}_{2}-\mathrm{CaO}\right.$ or $\left.\mathrm{SiO}_{2}-\mathrm{CaO}-\mathrm{P}_{2} \mathrm{O}_{5}\right)$ to be reached [2] and hybrid materials to be prepared [1,3]. Moreover complex architectures such as mesoporous [4,5] or macroporous 


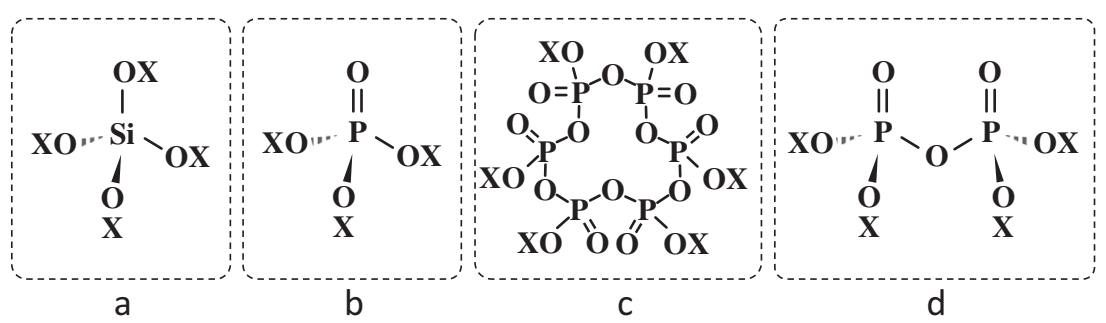

Fig. 1. Chemical formula of (a) Orthosilicate, (b) Orthophosphate, (c) Hexametaphosphate and (d) Pyrophosphate entities (X = H or R).

[6] materials including scaffolds [7], can be obtained thanks to integrative chemistry [8].

Other glass compositions involving major elements naturally present in the mineral phase of the human bone, namely phosphorus and calcium, have emerged as potential alternatives to bioactive silicate glasses. They are however highly degradable materials with fast dissolution rates, and they have been proposed for different limited clinical applications [9]. The sol-gel development of monolithic phosphate glasses using orthophosphate alkoxide precursors (Fig. 1-b) is another challenge that can be pointed out, especially due to the difficulty in reaching a "gelation" step considered as necessary to obtain monolithic glasses [10]. Phosphate alkoxides $\left(\mathrm{PO}(\mathrm{OR})_{3}\right)$ cannot be easily hydrolysed whereas phosphoric acid $\left(\mathrm{PO}(\mathrm{OH})_{3}\right)$ reacts too quickly and leads to precipitation rather than gelation. The use of $\left(\mathrm{PO}(\mathrm{OH})_{3-\mathrm{x}}(\mathrm{OR})_{\mathrm{x}}\right)$ species $(x=1,2)$ which exhibit chemical reactivities in between the previous families of phosphorus precursors has been proposed $(\mathrm{PO}(\mathrm{OH})$ $\mathrm{OBu}^{\mathrm{n}}$ and/or $\left.\mathrm{PO}(\mathrm{OH}) \mathrm{OBu}^{\mathrm{n}}\right)$ [11], but the use of toxic solvents (methanol, methoxyethanol) and the final temperature of heattreatment $\left(250^{\circ} \mathrm{C}\right)$ are not favourable for the further development of interesting materials and in particular for the preparation of hybrid organic-inorganic materials. The coacervation of polyphosphates such as the Graham salt (Fig. 1-c) has also been studied $[12,13]$ in order to form gels, however the resulting materials were not obtained in the form of monoliths but rather as powders or coatings [14], the conversion into monolithic materials only being possible after fusion $\left(800^{\circ} \mathrm{C}\right)$ or sintering [15], i.e. at temperatures incompatible with the development of hybrids.

An interesting alternative for the preparation of phosphatebased glasses by soft chemistry would be the use of pyrophosphate precursors (Fig. 1-d) whether in the form of salts or alkoxides. To the best of our knowledge, this approach has never been described in the literature despite a few publications showing the interesting properties of pyrophosphates in biomaterials applications (acellular and cellular in vitro tests [16,17], in vivo animal studies [18], and a clinical trial [19]).

The aim of this paper is to present an original strategy for the synthesis of novel pyrophosphate-based glasses by soft chemistry (low temperature, water solvent) and their physical chemical characterisation. Among different synthesis parameters, the effect of the $\mathrm{Ca}$ /Pyrophosphate ratio in the batch solution on the structure and the morphology of these new pyrophosphate glasses has been investigated, and the role of this ratio was more specifically analysed.

\section{Experimental section}

\subsection{Precursors}

The synthesis method involved calcium and pyrophosphate precursor salts. Anhydrous tetrapotassium pyrophosphate $\left(\mathrm{K}_{4} \mathrm{P}_{2} \mathrm{O}_{7}\right)$ was prepared by heating dipotassium hydrogen phosphate $\left(\mathrm{K}_{2} \mathrm{HPO}_{4}, \mathrm{VWR}\right.$, Analytical reagent, $\left.100 \mathrm{~g}\right)$ at $400{ }^{\circ} \mathrm{C}$ for $4 \mathrm{~h}$ in a muffle furnace. The as-synthesised anhydrous tetrapotassium pyrophosphate was characterised by Raman, FTIR and ${ }^{31} \mathrm{P}$ solid state NMR spectroscopies. The FTIR spectrum showed the characteristic vibrational modes of $\mathrm{P}_{2} \mathrm{O}_{7}^{4-}$ ions, and the total amount of orthophosphate units relative to pyrophosphates ( ${ }^{31} \mathrm{P}$ NMR) is less than $5 \%$ (data not presented). Analytical grade calcium chloride salt $\left(\mathrm{CaCl}_{2} \cdot 2 \mathrm{H}_{2} \mathrm{O}\right.$, Carlo Erba, ACS) was used as received, without further purification. The reagents were stored in a dry place without evidence of degradation after 6 months.

\subsection{Synthesis}

Calcium and pyrophosphate reagent solutions were prepared separately by dissolving $\mathrm{CaCl}_{2} \cdot 2 \mathrm{H}_{2} \mathrm{O}$ and $\mathrm{K}_{4} \mathrm{P}_{2} \mathrm{O}_{7}$ in deionised water (respectively in 20 and $200 \mathrm{~mL}$ ). Calcium solutions with different concentrations were tested in order to study the role of the calcium to pyrophosphate molar ratios $(\mathrm{Ca} / \mathrm{Pyro}$ or $\mathrm{Ca} / \mathrm{P})$ on the nature of the final material (PYG-XX); the higher the number XX after PYG in the sample name, the higher the reagent $\mathrm{Ca}$ /Pyro molar ratio used in the synthesis (Table 1 ). The calcium chloride solution was then added to the $\mathrm{K}_{4} \mathrm{P}_{2} \mathrm{O}_{7}$ solution using a peristaltic pump at a constant volumetric flowrate $\left(7.5 \mathrm{~mL} \mathrm{~min}^{-1}\right)$ for all samples. The mixture became translucent, and after the complete addition of the pyrophosphate reagent, the solution was stirred for five minutes, and the final colloidal solution was centrifuged $(7500 \mathrm{rpm})$. The resulting gel was washed several times with deionised water. Aliquots of the solution were collected during this step in order to measure the $\mathrm{pH}$ of the solution and the zeta potential of the formed particles. Particle diameters were measured by dynamic light scattering, but they are not presented here because of the lack of

Table 1

Concentrations of $\mathrm{Ca}^{2+}$ and $\mathrm{P}_{2} \mathrm{O}_{7}^{4-}$ in the precursor solutions, molar ratios, $\mathrm{pH}$ and zeta potential in the resulting batch.

\begin{tabular}{|c|c|c|c|c|c|c|c|}
\hline & PYG-00 & PYG-01 & PYG-02 & PYG-03 & PYG-04 & PYG-05 & PYG-06 \\
\hline$\left[\mathrm{CaCl}_{2}\right]\left(\mathrm{mol} \mathrm{L}^{-1}\right)$ & 0.180 & 0.270 & 0.360 & 0.451 & 0.541 & 0.631 & 0.721 \\
\hline$\left[\mathrm{K}_{4} \mathrm{P}_{2} \mathrm{O}_{7}\right]\left(\mathrm{mol} \mathrm{L}^{-1}\right)$ & 0.083 & & & & & & \\
\hline$\left(\mathrm{Ca}^{2+} / \mathrm{P}_{2} \mathrm{O}_{7}^{4-}\right)$ molar ratio & 0.216 & 0.325 & 0.433 & 0.541 & 0.649 & 0.758 & 0.866 \\
\hline$(\mathrm{Ca} / \mathrm{P})$ molar ratio & 0.108 & 0.162 & 0.216 & 0.271 & 0.325 & 0.379 & 0.433 \\
\hline $\mathrm{pH}$ & 9.55 & 9.30 & 9.06 & 9.00 & 8.74 & 8.45 & 8.34 \\
\hline Zeta potential $(\mathrm{mV})$ & -46.1 & -42.3 & -36.2 & -29.9 & -29.4 & -21.5 & -20.0 \\
\hline
\end{tabular}


repeatability due to the gelation occurring during the measurement period. The resulting transparent (PYG-00-PYG-03) or translucent (PYG-04-PYG-06) gel was poured into 24-well microplates and heated at $70{ }^{\circ} \mathrm{C}$ for 7 days.

The reference $\mathrm{Ca}_{10} \mathrm{~K}_{4}\left(\mathrm{P}_{2} \mathrm{O}_{7}\right)_{6} \cdot 9 \mathrm{H}_{2} \mathrm{O}$ crystalline phase was prepared with a protocol adapted from [20] (double decomposition). Briefly, Calcium reagent solution was prepared by dissolving Ca $\left(\mathrm{NO}_{3}\right)_{2} \cdot 2 \mathrm{H}_{2} \mathrm{O}(7.16 \mathrm{~g})$ in deionised water $(200 \mathrm{~mL})$. This solution was then added into a buffer solution containing pyrophosphate ions ( $5 \mathrm{~g}$ of $\mathrm{K}_{4} \mathrm{P}_{2} \mathrm{O}_{7}, 12 \mathrm{~mL}$ of acetic acid and a variable solution of ammonia to $400 \mathrm{~mL}$ of water, $\mathrm{pH} 7$ ) by using a peristaltic pump at a constant volumetric flowrate $\left(4.5 \mathrm{~mL} \mathrm{~min}^{-1}\right)$. The solution was stirred and heated at $90^{\circ} \mathrm{C}$. Then the precipitate was filtered using a Büchner funnel, washed three times with deionised water and finally dried in an oven at $37^{\circ} \mathrm{C}$ overnight.

\subsection{Characterisation of materials}

The synthesised materials were characterised by structural, microstructural, molecular, elemental and thermal characterisation methods.

Powder X-ray diffraction (XRD) measurements were performed at room temperature using a CPS 120 INEL diffractometer with a Co anticathode $\left(\lambda\left(K_{\alpha 1}\right)=1.789190 \AA\right.$ and $\left.\lambda\left(K_{\alpha 2}\right)=1.793210 \AA\right)$. Samples were ground before measurements. A stepsize of $0.03^{\circ}$ in the $2 \theta$ range $5-115^{\circ}$ was used.

All ${ }^{31} \mathrm{P}$ magic-angle spinning (MAS) NMR spectra were recorded at $14.1 \mathrm{~T}$, using a VNMRS-600 spectrometer operating at a ${ }^{31} \mathrm{P}$ Larmor frequency of $242.81 \mathrm{MHz}$. A Varian $3.2 \mathrm{~mm}$ HXY T3 MAS probe was used, spinning at $15 \mathrm{kHz}$. Single-pulse experiments were performed using the following parameters, which were verified to account for the actual relative quantities of the different phosphorous environments: $45^{\circ}{ }^{31} \mathrm{P}$ excitation pulse of $1.25 \mu \mathrm{s}$, spinal-64 ${ }^{1} \mathrm{H}$ decoupling (100 kHz RF) during acquisition, 90 s recycle delay, 4 scans (preceded by 4 dummy scans) $[21] .{ }^{1} \mathrm{H} \rightarrow{ }^{31} \mathrm{P}$ crosspolarization (CP) experiments were also performed at $15 \mathrm{kHz}$ MAS, using the following parameters: $90^{\circ}{ }^{1} \mathrm{H}$ excitation pulse of $2.5 \mu \mathrm{s}$, contact pulse of $0.3,1.0$ or $4.0 \mathrm{~ms}$, spinal- $64{ }^{1} \mathrm{H}$ decoupling (100 kHz RF) during acquisition, $4 \mathrm{~s}$ recycle delay, 120 scans (preceded by 2 dummy scans). Temperature regulation was used during all experiments, to ensure that the temperature inside the rotor was $\sim 20^{\circ} \mathrm{C}$. The ${ }^{31} \mathrm{P}$ chemical shifts were referenced to a synthetic hydroxyapatite phase, used as a secondary reference with respect to an $85 \% \mathrm{H}_{3} \mathrm{PO}_{4}$ solution.

Raman spectroscopy analyses were carried out using a confocal Raman microscope (Horiba Labram HR 800 Jobin Yvon). The samples were exposed to a continuous laser radiation provided by an AR-diode laser at $532 \mathrm{~nm}$, delivering $14 \mathrm{~mW}$ of power. The spectrum of each sample was acquired through a grating of $600 \mathrm{tr} / \mathrm{mm}$ with a spectral resolution of $1 \mathrm{~cm}^{-1}$ and collected with a quantum well detector cooled at $-60^{\circ} \mathrm{C}$ using a Synapse CCD. A certified silicon standard allowed a calibrating frequency of the equipment using the first order of silicon line at $520.7 \mathrm{~cm}^{-1}$. Each point of each sample was acquired with an integration time of $20 \mathrm{~s}$ and 4 accumulations. A baseline correction was performed using the software Labspec5 (Horiba).

Thermogravimetric analyses (TGA) and differential thermal analysis (DTA) were performed with Setaram instrumentation (Setsys Evolution System) from 30 to $900{ }^{\circ} \mathrm{C}$ at a heating rate of $5{ }^{\circ} \mathrm{C}$ per minute.

Scanning electron microscopy (SEM) observations were performed with a Leo 435 VP microscope. The accelerating voltage was fixed at $15 \mathrm{kV}$. Samples were gently crushed in a mortar, stuck on adhesive carbon discs and silver sputter-coated before observation.
Inductively coupled plasma - optical emission spectrometry (ICP-OES; Horiba Jobin Yvon Ultima 2 spectrometer) was used to determine the $\mathrm{Ca}, \mathrm{P}, \mathrm{K}$ and $\mathrm{Cl}$ concentrations. For this, $50 \mathrm{mg}$ of each sample were dissolved in $2 \mathrm{~mL}$ of $\mathrm{HNO}_{3}(2 \mathrm{M})$, and diluted with Milli-Q water $\left(25 \mathrm{mg} \mathrm{L}^{-1}\right)$. The instrument was calibrated using IAPSO Standard Seawater (OSIL, UK), which was diluted with Milli-Q water in various proportions. A standard was run during the course of the analyses to check for possible instrumental drift. All concentrations were drift and blank corrected. The standard error was lower than $2 \%$.

\section{Results}

Seven different Ca-pyrophosphate samples (PYG-00 to PYG-06) were prepared in water under mild conditions, using initial $\mathrm{Ca} /$ Pyro molar ratios ranging from $\sim 0.2$ to 0.9 (Table 1 ). Two synthesised materials (PYG-00 and PYG-06 on Fig. 2) present a different appearance depending on the Ca/Pyro ratio in the initial solution (precursors). While materials with lower calcium amounts (PYG00, 01, 02, 03) are translucent monoliths (Fig. 2-a) with good mechanical cohesion (it is difficult to grind these materials in a mortar), samples prepared with higher Ca/Pyro molar ratio (PYG04 to PYG-06) appear as white and friable materials (Fig. 2-b). These differences are confirmed by scanning electron microscopy micrographs (Fig. 3). For the PYG-00 sample (Fig. 3-a) prepared with the lowest amount of calcium, the particles appear to have angular shapes, smooth and compact fracture surfaces with irregular morphologies. These features are typical of those of a glassy material [22]. Fig. 3-b and c show an increase in the surface roughness for samples prepared by increasing the $\mathrm{Ca} /$ Pyro molar ratio (PYG-03 and PYG-06 materials). Precipitated particles of about $10 \mu \mathrm{m}$ can also be observed. They are embedded in an apparent non-crystalline matrix with a smooth surface at this scale (Fig. 3b). The amount of these precipitated particles seems to become

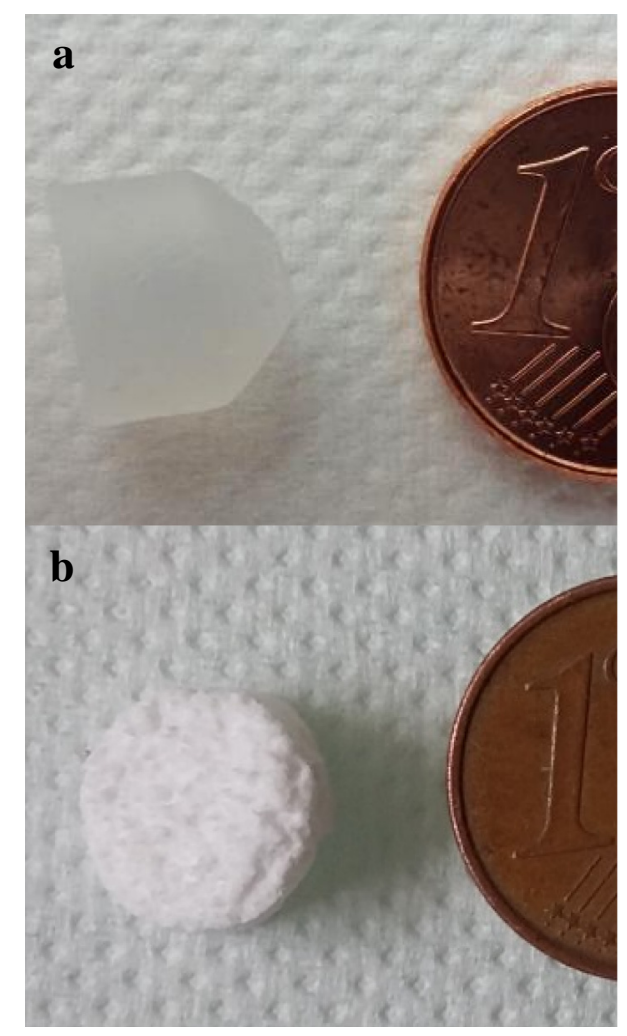

Fig. 2. Optical image of synthesised materials: PYG-00 (a), and PYG-06 (b). 

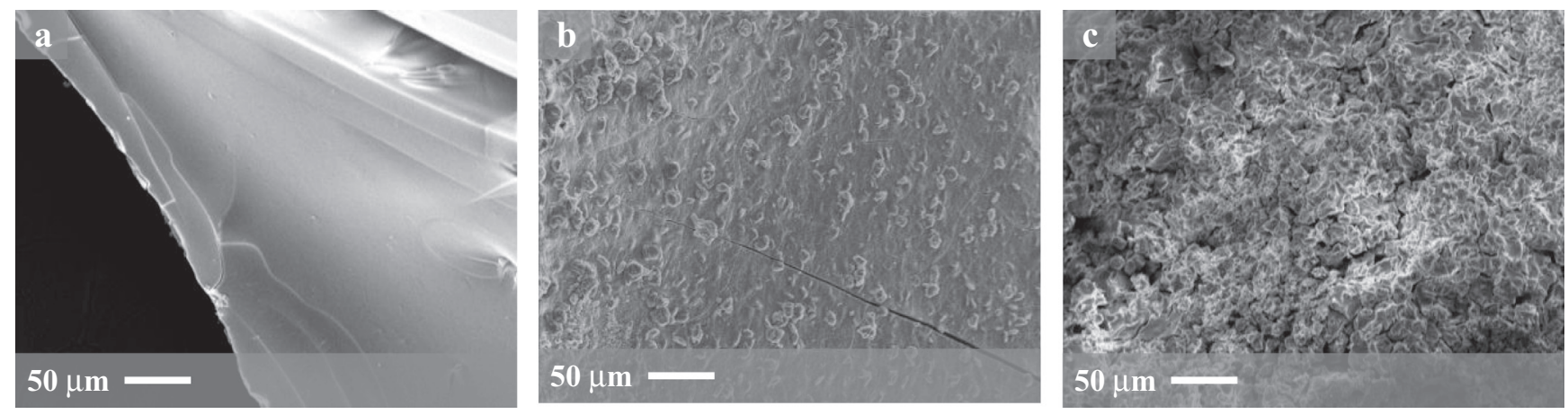

Fig. 3. SEM micrographs of the synthesised materials: PYG-00 (a), PYG-03 (b), PYG-06 (c).

particularly significant in sample PYG-06 (Fig. 3-c). This difference in sample morphology depending on the initial $\mathrm{Ca} /$ Pyro atomic ratio indicates that a second phase is progressively formed in the initial matrix which could be linked to the difference of visual appearance (from translucent to white) of the samples along the series.

The nature of the phases involved in all these synthesised materials was analysed by X-ray diffraction (Fig. 4-a). Samples PYG-00 and PYG-01 show one very broad halo centred around $35^{\circ}$ characteristic of the presence of an amorphous material with no longrange order. For sample PYG-02, this broad halo is still present but a series of sharp peaks appear. These sharp peaks become more and more intense as the initial Ca/Pyro ratio increases (from PYG02 to PYG-06 samples). These diffraction peaks were identified to correspond to a crystalline hydrated phase containing calcium, potassium and pyrophosphate ions with a hexagonal structure ( $\mathrm{P}_{3} \mathrm{~cm}$ space group): $\mathrm{Ca}_{10} \mathrm{~K}_{4}\left(\mathrm{P}_{2} \mathrm{O}_{7}\right)_{6} \cdot 9 \mathrm{H}_{2} \mathrm{O}$ [23] (Fig. 4-a).

Raman spectroscopy was used to study the vibrational modes of molecular entities in the synthesised materials. For the isolated $\mathrm{P}_{2} \mathrm{O}_{7}^{4-}$ ion (free ionic group) in the $\mathrm{C}_{2 \mathrm{v}}$ symmetry, twenty-one Raman active modes can be predicted [24]. All these lines are not resolved and seven domains can be distinguished. Six domains can be attributed to pyrophosphates: $v^{\text {as }} \mathrm{PO}_{3}$, between 1100 and $1300 \mathrm{~cm}^{-1}, v^{s} \mathrm{PO}_{3}$, around $1045 \mathrm{~cm}^{-1}, v^{\text {as }} \mathrm{POP}$, around $907 \mathrm{~cm}^{-1}$,
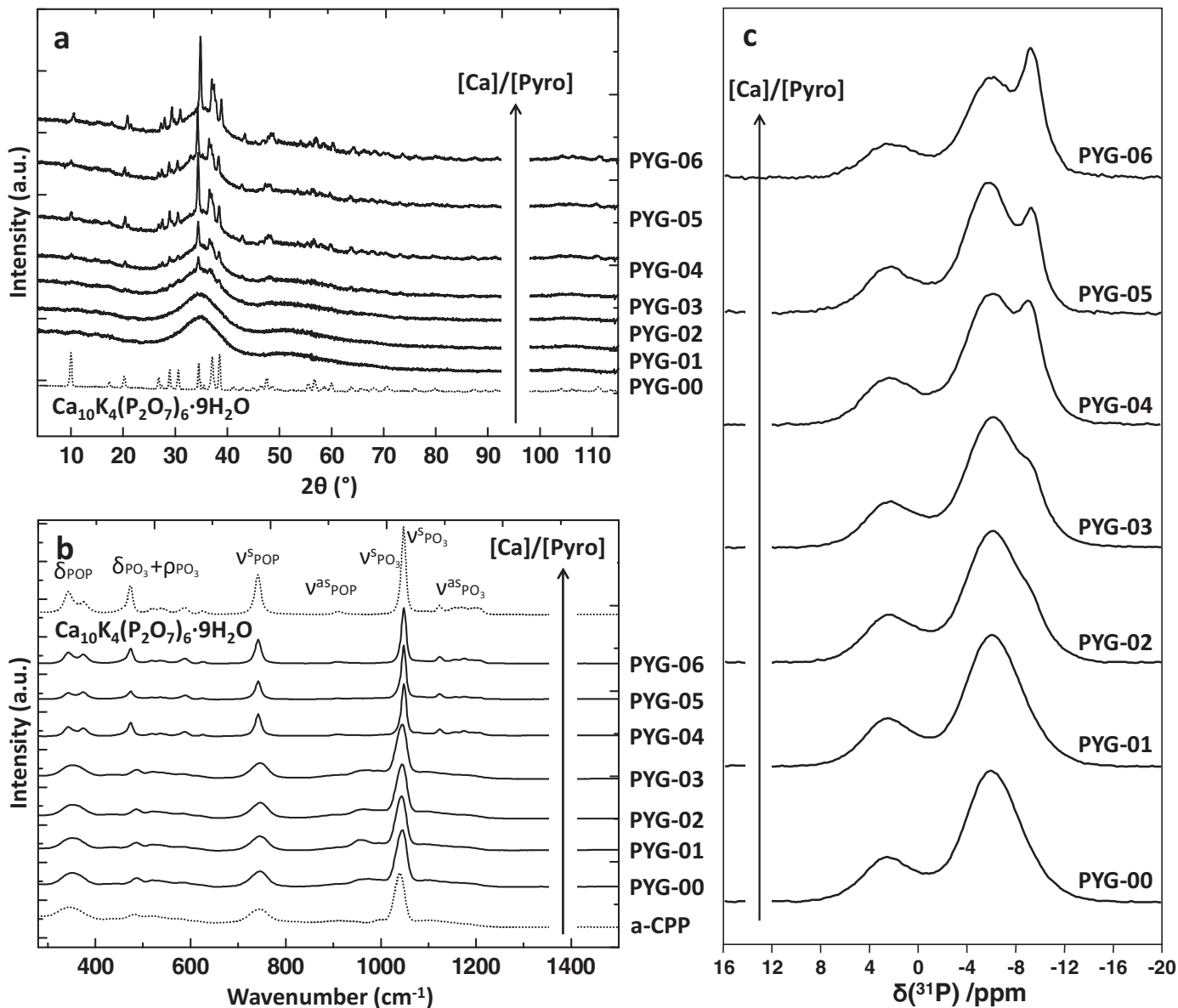

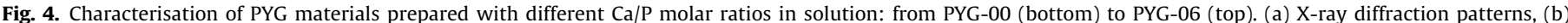

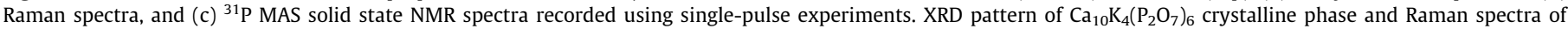
$\mathrm{Ca}_{10} \mathrm{~K}_{4}\left(\mathrm{P}_{2} \mathrm{O}_{7}\right)_{6}$ crystalline phase and of pure amorphous calcium pyrophosphate (a-CPP [20]) are also presented. 
$v^{\mathrm{s}} \mathrm{POP}$, around $740 \mathrm{~cm}^{-1}, \delta \mathrm{PO}_{3}$ and $\rho \mathrm{PO}_{3}$ between 440 and $645 \mathrm{~cm}^{-1}$, and $\delta$ POP and between 315 and $400 \mathrm{~cm}^{-1}$. The last domain between 930 and $990 \mathrm{~cm}^{-1}$ is related to the $\mathrm{v}^{\mathrm{as}} \mathrm{PO}_{3}$ band of orthophosphate entities. Pyrophosphate broad bands are observed from PYG-00 to PYG-03, respectively at 348, 746 and $1045 \mathrm{~cm}^{-1}$ for $\delta$ POP, $v^{\mathrm{s}} \mathrm{POP}$ and $v^{\mathrm{s}} \mathrm{PO}_{3}$ (Fig. $4 \mathrm{~b}$ ). These broad bands are typical of amorphous calcium pyrophosphate phases (a-CPP) [20]. The band associated to orthophosphates is also present on these spectra. For PYG-04, PYG-05 and PYG-06, pyrophosphate bands are sharper and can be related to $\mathrm{Ca}_{10} \mathrm{~K}_{4}\left(\mathrm{P}_{2} \mathrm{O}_{7}\right)_{6} \cdot 9 \mathrm{H}_{2} \mathrm{O}$ crystalline phase (Fig. 4-b). The orthophosphate band $\left(960 \mathrm{~cm}^{-1}\right)$ is not detected for these three materials.

${ }^{31} \mathrm{P}$ solid state NMR spectra were recorded for all the samples using single-pulse excitation experiments (Fig. 4-c). For PYG-00 and PYG-01, two distinct resonances are observed at $\sim-5.9$ and $\sim+2.3 \mathrm{ppm}$, which can be assigned to pyrophosphate and orthophosphate entities, based on previous NMR studies on calcium (pyro)phosphates [25-27]. This assignment was also confirmed by additional $1 \mathrm{D}{ }^{31} \mathrm{P}$ INADEQUATE NMR experiments (Incredible Natural Abundance DoublE QUAntum Transfer Experiment - see Supplementary material, Fig. S1). As the Ca/Pyro ratio increases from PYG-02 to PYG-06, a second more narrow pyrophosphate resonance (centred at $\sim-9.3 \mathrm{ppm}$ ) progressively appears, which can be assigned to the $\mathrm{Ca}_{10} \mathrm{~K}_{4}\left(\mathrm{P}_{2} \mathrm{O}_{7}\right)_{6} \cdot 9 \mathrm{H}_{2} \mathrm{O}$ phase identified by XRD. The deconvolution of the ${ }^{31} \mathrm{P}$ NMR signals confirms that the relative concentration of this crystalline phase globally increases along the series, to the detriment of the more amorphous pyrophosphate environments (Table 3 ).

The thermal evolution of samples was checked by TGA-DTA. Fig. 5 shows the TGA and DTA curves respectively, of PYG-00, PYG-03 and PYG-06. The TGA curves exhibit two distinct regions of mass loss for PYG-00 and PYG-03 and an almost continuous curve for PYG-06. The mass losses can be attributed to the release of water either adsorbed or associated with the mineral structures (in particular the first mass loss associated to an endothermic event before $150^{\circ} \mathrm{C}$ ). The final mass losses (plateau after $600{ }^{\circ} \mathrm{C}$ ) were $14.3 \%, 13.0 \%$ and $12.3 \%$ for PYG-00, PYG-03 and PYG-06, respectively. We recall here that PYG-00 was found to be purely amorphous and PYG-06 to be composed of crystalline and amorphous phases. The beginning of the plateau (around $150{ }^{\circ} \mathrm{C}$ ) corresponds to an exothermic event followed by a sharp endothermic peak. Complementary investigations by XRD on samples heated at $200{ }^{\circ} \mathrm{C}$ (Supplementary material, S2) indicate the formation of monetite and apatite crystals. The Raman spectra show a shift of the line assigned to orthophosphate toward higher wavenumbers corresponding to calcium phosphate apatite, however monetite could not be clearly identified. These data suggest the crystallisation of orthophosphate moieties present in the glass into apatite and monetite phases. The formation of additional orthophosphate ions could also result from the endothermic hydrolysis of pyrophosphate ions into orthophosphate (Eq. (1)), as reported for other hydrated calcium pyrophosphates.

$\mathrm{P}_{2} \mathrm{O}_{7}^{4-}+\mathrm{H}_{2} \mathrm{O} \leftrightarrows 2 \mathrm{HPO}_{4}^{2-}$

As the amorphous phase is still present at $250{ }^{\circ} \mathrm{C}$, the mass loss above this temperature could be attributed to the loss of water molecules involved in this phase and the condensation of $\mathrm{HPO}_{4}^{2-}$ into pyrophosphate ions (reverse reaction of Eq. (1)) corresponding to the disappearance of monetite. At higher temperatures, two exothermic peaks (580 and $620^{\circ} \mathrm{C}$ ) occur, probably corresponding to a condensation of hydrogenophosphates into pyrophosphates followed by a crystallisation event corresponding to the formation of a high-temperature crystalline calcium pyrophosphate phase $\left(\beta-\mathrm{Ca}_{2} \mathrm{P}_{2} \mathrm{O}_{7}\right.$ structure [27]). For PYG-06, the mass loss was continuous (dehydration) until $600{ }^{\circ} \mathrm{C}$.
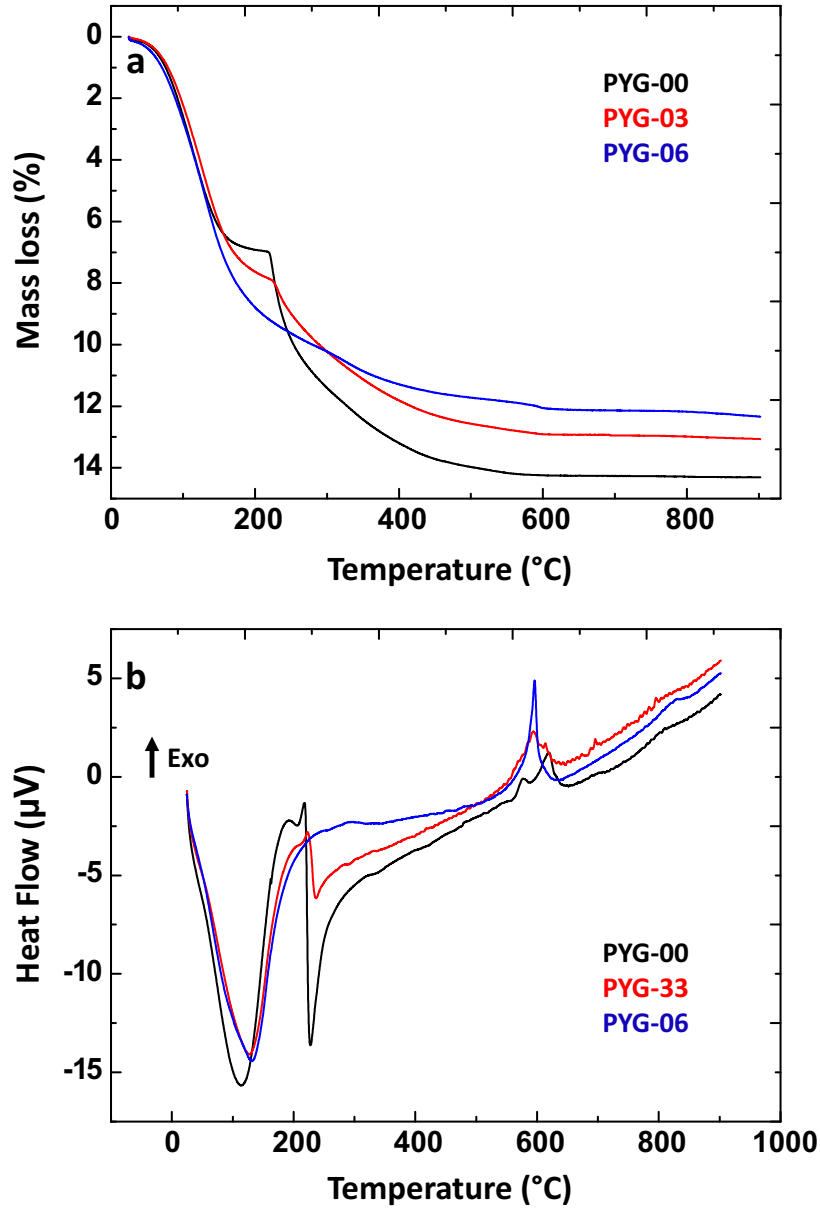

Fig. 5. (a) TGA and (b) DTA curves for PYG-00, PYG-03, and PYG-06 synthesised materials.

\section{Discussion}

\subsection{Nature, structure and composition of the as-synthesised materials}

Macroscopic and microscopic observations combined with $\mathrm{X}$ ray diffraction, Raman spectroscopy, and ${ }^{31} \mathrm{P}$ solid state NMR analyses suggest that i) Monolithic and translucent materials (PYG-00 and PYG-01) can be considered as glasses (angular shapes, smooth and compact surfaces, irregular fractures morphologies) with amorphous characteristics (broad bands in Raman spectroscopy, broad peaks in ${ }^{31} \mathrm{P}$ MAS NMR, and absence of XRD sharp peaks) although they do not show a vitreous transition; ii) Glassceramics are formed for the other compositions (PYG-02 to PYG-06) and the crystalline part increases as the initial Ca/Pyro ratio is increased (nucleation and crystal growth of precipitates, increase of sharp peaks in XRD, and of sharp bands in Raman spectroscopy, appearance of a narrow ${ }^{31} \mathrm{P}$ signal in solid state NMR), which leads to a decrease of cohesiveness of the material.

Considering the chemical composition of materials (Table 2), the ${ }^{31} \mathrm{P}$ solid state NMR results (Table 3 ) and the XRD patterns, the glassy phase (PYG-00) is mainly composed of calcium, pyrophosphate and to a lesser extent by orthophosphate (formed through a partial hydrolysis of pyrophosphate, during one of the synthesis steps: initial solution, centrifugation and gel washing step, and/or final thermal treatment) and potassium ions. In order to understand the nature of this material, the comparison with melt-derived glasses is an interesting approach. The description 
Table 2

Elemental composition of the synthesised materials and atomic ratios determined by ICP-AES analysis.

\begin{tabular}{|c|c|c|c|c|c|c|c|}
\hline & PYG-00 & PYG-01 & PYG-02 & PYG-03 & PYG-04 & PYG-05 & PYG-06 \\
\hline $\mathrm{Ca}(\mathrm{mol} / 100 \mathrm{~g})$ & $0.547 \pm 0.011$ & $0.613 \pm 0.012$ & $0.605 \pm 0.012$ & $0.582 \pm 0.012$ & $0.556 \pm 0.011$ & $0.543 \pm 0.011$ & $0.537 \pm 0.011$ \\
\hline $\mathrm{K}(\mathrm{mol} / 100 \mathrm{~g})$ & $0.184 \pm 0.004$ & $0.160 \pm 0.003$ & $0.177 \pm 0.004$ & $0.198 \pm 0.004$ & $0.217 \pm 0.004$ & $0.276 \pm 0.006$ & $0.237 \pm 0.005$ \\
\hline $\mathrm{P}(\mathrm{mol} / 100 \mathrm{~g})$ & $0.610 \pm 0.012$ & $0.665 \pm 0.013$ & $0.665 \pm 0.013$ & $0.651 \pm 0.013$ & $0.632 \pm 0.013$ & $0.640 \pm 0.013$ & $0.625 \pm 0.012$ \\
\hline $\mathrm{Cl}(\mathrm{mol} / 100 \mathrm{~g})$ & $0.003 \pm 0.169$ & $0.004 \pm 0.217$ & $0.005 \pm 0.241$ & $0.006 \pm 0.307$ & $0.009 \pm 0.446$ & $0.014 \pm 0.716$ & $0.014 \pm 0.699$ \\
\hline $\mathrm{Ca} / \mathrm{P}$ atomic ratio & $0.897 \pm 0.036$ & $0.922 \pm 0.037$ & $0.910 \pm 0.036$ & $0.895 \pm 0.036$ & $0.879 \pm 0.035$ & $0.849 \pm 0.034$ & $0.860 \pm 0.034$ \\
\hline $\mathrm{K} / \mathrm{P}$ atomic ratio & $0.302 \pm 0.012$ & $0.240 \pm 0.010$ & $0.266 \pm 0.011$ & $0.305 \pm 0.012$ & $0.342 \pm 0.014$ & $0.431 \pm 0.017$ & $0.380 \pm 0.015$ \\
\hline $\mathrm{Ca} / \mathrm{K}$ atomic ratio & $2.975 \pm 0.119$ & $3.837 \pm 0.153$ & $3.423 \pm 0.137$ & $2.936 \pm 0.117$ & $2.568 \pm 0.103$ & $1.969 \pm 0.079$ & $2.264 \pm 0.091$ \\
\hline
\end{tabular}

Table 3

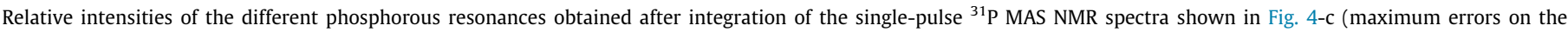
absolute values of the intensities of the P resonances - in \% - are estimated to $\sim 3 \%$ ).

\begin{tabular}{|c|c|c|c|c|c|}
\hline & \multicolumn{3}{|c|}{ Intensity of the different $\mathrm{P}$ resonances (\%) } & \multicolumn{2}{|c|}{$\begin{array}{l}\text { Relative intensity of the different } \mathrm{P} \\
\text { resonances }\end{array}$} \\
\hline & Ortho $\left(\delta_{\text {iso }} \sim 2.3 \mathrm{ppm}\right)$ & Pyro1 ( $\left.\delta_{\text {iso }} \sim-5.9 \mathrm{ppm}\right)$ & Pyro2 (cryst) $\left(\delta_{\text {iso }} \sim-9.3 \mathrm{ppm}\right)$ & Ortho/Pyro1 & Pyro2/Pyro1 \\
\hline PYG-00 & $17 \%$ & $83 \%$ & - & 0.20 & - \\
\hline PYG-01 & $18 \%$ & $82 \%$ & - & 0.22 & - \\
\hline PYG-02 & $18 \%$ & $75 \%$ & $7 \%$ & 0.24 & 0.09 \\
\hline PYG-03 & $16 \%$ & $73 \%$ & $11 \%$ & 0.22 & 0.15 \\
\hline PYG-04 & $16 \%$ & $63 \%$ & $21 \%$ & 0.25 & 0.33 \\
\hline PYG-05 & $23 \%$ & $56 \%$ & $21 \%$ & 0.41 & 0.38 \\
\hline PYG-06 & $16 \%$ & $55 \%$ & $29 \%$ & 0.29 & 0.53 \\
\hline
\end{tabular}

of melt-derived binary calcium phosphate glasses $\left(\mathrm{P}_{2} \mathrm{O}_{5}-\mathrm{CaO}\right)$ is usually based on the connectivity of $\mathrm{PO}_{4}$ tetrahedra (basic structure units), and the nomenclature of $\mathrm{Q}^{[\mathrm{n}]}$ groups is generally used, where $[\mathrm{n}]$ is the number of bridging oxygen atoms per $\mathrm{PO}_{4}$ tetrahedron. Several domains can be distinguished according to the $\mathrm{Ca} / \mathrm{P}$ ratio in the material [28]:

- Ultraphosphate glasses: $\mathrm{Q}^{3}$ and $\mathrm{Q}^{2}$ species and $0<\mathrm{Ca} / \mathrm{P}<0.5$.

- Metaphosphate glasses: $\mathrm{Q}^{2}$ species and $\mathrm{Ca} / \mathrm{P}=0.5$.

- Polyphosphate glasses: $\mathrm{Q}^{2}$ and $\mathrm{Q}^{1}$ species and $\mathrm{Ca} / \mathrm{P}>0.5$.

- Pyrophosphate glasses: $\mathrm{Q}^{1}$ species and $\mathrm{Ca} / \mathrm{P}=1$.

- Invert glasses: $\mathrm{Q}^{1}$ and $\mathrm{Q}^{0}$ species and $\mathrm{Ca} / \mathrm{P}>1$.

Even if the processes used for the synthesis are not the same (soft chemistry vs "melt quench" processing), the lowtemperature glasses described in the present article (particularly PYG-00 and PYG-01) with $\mathrm{Q}^{1}$ and $\mathrm{Q}^{0}$ species and $\mathrm{Ca} / \mathrm{P}>1$ belong to the "invert glasses" type. Such glasses do not have a continuous random network of glass forming polyhedral $\left(\mathrm{PO}_{4}\right)$, but are formed of small molecular phosphate ions (one or two phosphorus) linked together through bivalent "bridging" calcium. Invert melt-derived glasses tend easily to crystallize (easier diffusion due to the small size of the phosphate moieties involved) and the incorporation of intermediate oxides such as $\mathrm{TiO}_{2}$ [29] can be necessary for their synthesis. However, it is important to note here that beyond the economic perspective associated with the process used for preparing the PYG phases (low temperature, water solvent, and low cost precursors), it does not need any glass forming additives.

In addition to calcium, pyrophosphates, and orthophosphates, PYG glasses contain water, and TGA-DTA analysis provides information on the localisation of water molecules. Indeed, between $25^{\circ} \mathrm{C}$ and $100{ }^{\circ} \mathrm{C}$, the TGA curves of the samples are similar, but the peak of PYG-00 is more endothermic than for PYG-03 and PYG-06, which are both glass-ceramics containing the crystalline hydrated phase $\mathrm{Ca}_{10} \mathrm{~K}_{4}\left(\mathrm{P}_{2} \mathrm{O}_{7}\right)_{6} \cdot 9 \mathrm{H}_{2} \mathrm{O}$. It means that for the same overall amount of water, $\mathrm{H}_{2} \mathrm{O}$ molecules are energetically more linked to their environment for PYG-00 than for PYG-03 and PYG-06. So, it can be assumed that a part of water molecules are involved in the amorphous network and not only adsorbed at the interfaces. Solid state NMR analyses are consistent with this assumption. Indeed, one main broad resonance centred at $\sim 5.1 \mathrm{ppm}$ was observed on the ${ }^{1} \mathrm{H}$ MAS NMR spectra of the materials (which is consistent with the presence of water), and ${ }^{1} \mathrm{H} \rightarrow{ }^{31} \mathrm{P}$ cross-polarisation MAS experiments show that the different ortho and pyrophosphate anions are all in close vicinity to protons (Supplementary material, Fig. S3). Until $190^{\circ} \mathrm{C}$ DTA differences between PYG-00 and PYG-06 could be attributed to the presence of the mass loss plateau. This plateau indicates two different kinds of water release: from 20 to $218^{\circ} \mathrm{C}$ (see Supplementary material, Fig. S4) it could be associated to weakly-bonded water (also present in PYG-06), and after $218{ }^{\circ} \mathrm{C}$ to a fast removal of water from the glass as demonstrated by an abrupt mass loss. This abrupt phenomenon is due to an event occurring at a well-defined temperature in an amorphous material. One could propose that this phenomenon could be a kind of a glass transition in this hydrated glass. This assertion could be supported by several arguments: i) the fast release (demonstrated both by DTA and TGA variations at $218^{\circ} \mathrm{C}$ ) of water and ii) the crystallisation of orthophosphatebased phases (monetite and apatite) in a pyrophosphate-rich matrix, could be a consequence of the decrease of the viscosity and consequently the increase of the mobility of small molecules and ions, iii) finally it corresponds to a small endothermic peak $\left(206^{\circ} \mathrm{C}\right.$, before the orthophosphate crystallisation peak) which is not explained by a mass loss.

Even if the structure will need further characterisations to be fully determined (in particular using pair distribution functions derived from synchrotron X-ray data as well as more advanced solid state NMR experiments including ${ }^{43} \mathrm{Ca}$ NMR [25]) a general chemical formula (Eq. (2)) can be proposed at this stage to describe these new glasses, by combining ${ }^{31} \mathrm{P}$ solid state NMR, ICP-AES, and TGA-DTA analysis results:

$\left\{\left[(\mathrm{Ca} 2+)_{1-\mathrm{x}}\left(\mathrm{H}^{+} / \mathrm{K}^{+}\right)_{2 \mathrm{x}}\right]_{2}\left[\left(\mathrm{P}_{2} \mathrm{O}_{7}^{4-}\right)_{1-\mathrm{y}}\left(\mathrm{PO}_{4}^{3-}\right)_{4 \mathrm{y} / 3}\right]\right\} \mathrm{n}\left(\mathrm{H}_{2} \mathrm{O}\right)$

where $\mathrm{n}$ is the weight percent of water. In the case of PYG-00, we determined that the chemical formula (Eq. (3)) is:

$\left\{\left[\left(\mathrm{Ca}^{2+}\right)_{0.83}\left(\mathrm{H}^{+} / \mathrm{K}^{+}\right)_{0.35}\right]_{2}\left[\left(\mathrm{P}_{2} \mathrm{O}_{7}^{4-}\right)_{0.76}\left(\mathrm{PO}_{4}^{3-}\right)_{0.31}\right]\right\} 14.3\left(\mathrm{H}_{2} \mathrm{O}\right)$

This formula is interesting because it highlights the role of pyrophosphates as forming entities, $\mathrm{Ca}^{2+}$ as bridging bivalent cations between phosphate species (pyro and/or orthophosphates) and protons $/ \mathrm{K}^{+}$as non-bridging ions. 


\subsection{Formation of the monolithic amorphous phase}

A key point of this study is the understanding of why a glass is formed with lower initial Ca/Pyro ratios, while glass-ceramics are formed for higher ones. Considering the results, one may wonder if calcium concentration is not a key point in the process of pyrophosphate glass formation: a low concentration could prevent the crystallisation of PYG-00 and PYG-01. However, a sample synthesised under the same conditions as PYG-00, but without the washing steps was shown in the SEM micrographs (Fig. S5, Supplementary material) to include several crystal morphologies (embedded in an amorphous matrix) characteristic of crystalline hydrated calcium pyrophosphate phases, which were identified by XRD (Fig. S5, Supplementary material) as triclinic calcium pyrophosphate dihydrate (t-CPPD, $\mathrm{Ca}_{2} \mathrm{P}_{2} \mathrm{O}_{7} \cdot 2 \mathrm{H}_{2} \mathrm{O}$ ) (Fig. $\mathrm{S} 5$, A crystal type), monoclinic pyrophosphate tetrahydrate beta (m-CPPT $\beta, \mathrm{Ca}_{2} \mathrm{P}_{2} \mathrm{O}_{7}$. $4 \mathrm{H}_{2} \mathrm{O}$ ) (Fig. S5, B and C crystal types) [20] and $\mathrm{Ca}_{10} \mathrm{~K}_{4}\left(\mathrm{P}_{2} \mathrm{O}_{7}\right)_{6} \cdot 9 \mathrm{H}_{2} \mathrm{O}$ (Fig. S5, D crystal type). These results demonstrate that PYG-00 can thermodynamically evolve towards crystalline phases with similar chemical composition. So, one can assume that a transient amorphous phase is formed during the first step of the synthesis. The evolution of this amorphous phase into a crystalline phase is apparently avoided by the washing step and the formation of the final amorphous phase is kinetically driven as generally observed. However, an increase in the initial amount of calcium from PYG-02 to PYG-06 (Table 1) allows for the formation of the $\mathrm{Ca}_{10} \mathrm{~K}_{4}\left(\mathrm{P}_{2} \mathrm{O}_{7}\right)_{6}$. $9 \mathrm{H}_{2} \mathrm{O}$ phase, even after the washing step. Another and complementary assumption is based on the surface charges of the initial nuclei. Zeta potentials were measured for all the samples in the batch solutions (Table 1). Particles leading to amorphous samples (such as PYG-00) are more charged than those leading to glassceramics (PYG-06). This charge is decreased with the increase of the calcium concentration in the precursor solution added. Indeed when more calcium is added, the ionic strength of the solution is increased. These results suggest that the lower ionic strength of synthesis solution for PYG-00 can prevent their aggregation (high surface charges) and then their evolution toward crystalline phases. The ICP-AES analyses (Table 2 ) show that the $\mathrm{Ca} / \mathrm{P}$ ratio in the final materials was quite equivalent (between 0.848 and 0.921 ) and close the $\mathrm{Ca} / \mathrm{P}$ ratio of $\mathrm{Ca}_{10} \mathrm{~K}_{4}\left(\mathrm{P}_{2} \mathrm{O}_{7}\right)_{6} \cdot 9 \mathrm{H}_{2} \mathrm{O}$ phase (0.83). As previously stated, kinetics is preponderant and the addition of the calcium solution (increased concentration from PYG-00 to PYG-06) was achieved with a constant volumetric flow rate. Consequently for a given time during the synthesis, the evolution of PYG-06 from an amorphous to a crystalline state is more advanced and could then explain the structural differences (glasses versus glass-ceramics).

The amorphous state of nuclei and their evolution in the initial solution is also an interesting question. The existence of amorphous calcium phosphate nanoprecursors is still discussed $[30,31]$ and models have been developed to explain their possible stabilisation by surface species and crystallisation inhibitors (such as amino acids) [32]. In our case, the stabilisation of amorphous nuclei could be explained by several hypotheses that are not mutually exclusive. The first one is related to the large range of geometric configurations for pyrophosphate anions. Indeed, considering the Raman spectrum (Fig. 5-b) of PYG-00 (and contrary to glassceramic samples) the bands associated to P-O-P vibrations ( $v^{\mathrm{s}} \mathrm{POP}$, $v^{\text {as }} \mathrm{POP}$ ) are broad. According to Lazarev [33], who suggested an empirical relationship between the $\mathrm{P}-\mathrm{O}-\mathrm{P}$ angle $\theta$ and these vibrations (Eq. (4)), it can be assumed that these broad bands can be partially associated to a large domain of angle conformation (it is correlated with ${ }^{31} \mathrm{P}$ NMR broad signals). The latter could then impede the formation of a crystalline structure during the first step of the synthesis [27]. The structural degrees of freedom of pyrophosphate entities and probably their size (bigger than orthophosphate) slow down diffusion (steric hindrance), and could then increase the stability of the amorphous phase.

$$
\Delta=\left(v^{a s} \mathrm{POP}-v^{2} \mathrm{POP}\right) /\left(v^{a s} \mathrm{POP}+v^{s} \mathrm{POP}\right)=f(\theta)
$$

Finally, the presence of orthophosphate in PYG (as demonstrated by solid state NMR) could also play a key role in the amorphous state of nuclei. Pyrophosphate ions are well-known inhibitors of orthophosphate phases crystallisation in vitro and in vivo [34,35], because they prevent the growth of organised domains due to surface interaction [36,37] but also could affect the organisation of phases due to size or ion charge effect. By mirror effect, this explanation could be applied to a possible inhibition of the crystallisation of calcium pyrophosphate phases by orthophosphates ions. Indeed, Gras [38] showed that the presence of orthophosphate has always been found to be higher in amorphous calcium pyrophosphate phases than in the crystalline ones. It is not clear at this stage if this observation could be related to disproportionation effect reported in polyphosphate glasses $[28,39]$, an internal hydrolysis of pyrophosphate ions or simply an easier incorporation of impurities in disorganised structures.

All in all, it appears that the reactant system used here was particularly well suited for the formation of a new class of Ca-phosphate-based glasses, due to the specific structure and reactivity of the pyrophosphate anions involved.

\section{Conclusion}

For the first time, the synthesis of monolithic calcium phosphate glasses at low temperature $\left(70^{\circ} \mathrm{C}\right)$ has been described. According to the initial $\mathrm{Ca} /$ Pyrophosphate molar ratio, a glass (mixed calcium pyro-orthophosphate phase containing potassium and water) or a glass-ceramic $\left(\mathrm{Ca}_{10} \mathrm{~K}_{4}\left(\mathrm{P}_{2} \mathrm{O}_{7}\right)_{6} \cdot 9 \mathrm{H}_{2} \mathrm{O}\right.$ crystals embedded in the amorphous phase) was formed. The proportion of the crystalline phase increased with an increase in the Ca/Pyrophosphate ratio in the batch solution. It was demonstrated that the formation of the glassy material is not thermodynamically but rather kinetically driven and that the evolution of a transient amorphous phase toward a crystalline phase could be avoided by the washing step. The amorphous state of nuclei of glasses could be explained by i) the ionic strength of the initial solution, ii) the structural degrees of freedom of pyrophosphate entities and iii) the inhibitory effect of orthophosphate ions on calcium pyrophosphate phase crystallisation. Even if the different mechanisms involved in the formation of such materials (chemical, structural, and morphological evolution during the synthesis steps) are still to be investigated in detail, the synthesis of these new monolithic calcium pyrophosphate glasses in water-based solvent and at a low temperature opens up many perspectives to develop the chemistry of low-temperature calcium pyrophosphate-based materials for various applications. In the field of materials for bone substitution, these novel materials and their synthesis process should be particularly well-suited to the preparation of hybrid organic-inorganic biomaterials, involving delicate biomolecules such as enzymes or growth factors.

\section{Author information}

Author contributions: All authors contributed to the preparation of this manuscript.

Notes: The authors declare no competing financial interest.

\section{Acknowledgments}

The authors would like to thank Dr. Mallorie Tourbin (Laboratoire de Génie Chimique UMR 5503, Toulouse, France) for 
preliminary zeta potential measurements and the Agence Nationale de la Recherche (CAPYROSIS project - grant n ${ }^{\circ}$ ANR-12-BSO80022-01) for supporting part of this research work.

\section{Appendix A. Supplementary data}

Supplementary data associated with this article can be found, in the online version, at http://dx.doi.org/10.1016/j.actbio.2016.05. 030.

\section{References}

[1] L.L. Hench, The story of Bioglass, J. Mater. Sci. - Mater. Med. 17 (2006) $967-$ 978.

[2] D. Arcos, D.C. Greenspan, M. Vallet-Regi, Influence of the stabilization temperature on textural and structural features and ion release in $\mathrm{SiO}_{2}$ CaO- $\mathrm{P}_{2} \mathrm{O}_{5}$ sol-gel glasses, Chem. Mater. 14 (2002) 1515-1522.

[3] L.S. Connell, F. Romer, M. Suárez, E.M. Valliant, Z. Zhang, P.D. Lee, M.E. Smith, J. V. Hanna, J.R. Jones, Chemical characterisation and fabrication of chitosansilica hybrid scaffolds with 3-glycidoxypropyl trimethoxysilane, J. Mater. Chem. B 2 (2014) 668-680.

[4] A. Lopez-Noriega, D. Arcos, Y. Sakamoto, O. Terasaki, M. Vallet-Regi, Ordered mesoporous bioactive glasses for bone tissue regeneration, Chem. Mater. 18 (2006) 3137-3144.

[5] J. Soulié, J. Lao, E. Jallot, J.M. Nedelec, Influence of mesostructuration on the reactivity of bioactive glasses in biological medium: a PIXE-RBS study, J. Mater Chem. 22 (22) (2012) 20680-20688.

[6] J. Soulié, A. Hardy-Dessources, J.M. Nedelec, E. Jallot, 3D organized macroporous bioactive glasses: a study of pore size effect on physicochemical reactivity by micro-PIXE-RBS, J. Phys. Chem. C 117 (2013) 6702-6711.

[7] J.R. Jones, Review of bioactive glass: from Hench to hybrids, Acta Biomater. 9 (2013) 4457-4486.

[8] R. Backov, Combining soft matter and soft chemistry: integrative chemistry towards designing novel and complex multiscale architectures, Soft Matter 2 (2006) 452-464.

[9] J.C. Knowles, Phosphate based glasses for biomedical applications, J. Mater Chem. 13 (2003) 2395-2401.

[10] J. Livage, Ph. Barboux, M.T. Vendenborre, C. Schmutz, F. Taulelle, Sol-gel synthesis of phosphates, J. Non-Cryst. Solids 147 (1992) 18-23.

[11] D.M. Pickup, P. Guerry, R.M. Moss, J.C. Knowles, M.E. Smith, R.J. Newport, New sol-gel synthesis of a $(\mathrm{CaO})_{0.3}\left(\mathrm{Na}_{2} \mathrm{O}\right)_{0.2}\left(\mathrm{P}_{2} \mathrm{O}_{5}\right)_{0.5}$ bioresorbable glass and its structural characterization, J. Mater. Chem. 17 (2007) 4777-4784.

[12] G. Willot, F. Gomez, P. Vast, V. Andries, M. Martines, Y. Messaddeq, M. Poulain, Preparation of zinc sodium polyphosphates glasses from coacervates precursors. Characterisation of the obtained glasses, and their applications, Comptes Rendus Chim. 5 (2002) 899-906

[13] F. Delahaye, L. Montagne, G. Palavit, J. Claude Touray, P. Baillif, Acid dissolution of sodium-calcium metaphosphate glasses, J. Non-Cryst. Solids 242 (1998) 25-32.

[14] D.M. Pickup, RJ. Newport, E.R. Barney, J.Y. Kim, S.P. Valappil, J.C. Knowles, Characterisation of phosphate coacervates for potential biomedical applications, J. Biomater. Appl. 28 (2014) 1226-1234.

[15] M. Draoui, Application du procédé sol-gel/verre à l'obtention de materiaux phosphates utilisables en genie biomedical (Ph.D. thesis), Université de Lille, 1985. 53.

[16] L.M. Grover, A. Wright, U. Gbureck, A. Bolarinwa, J. Song, Y. Liu, D.F. Farrar, G. Howling, J. Rose, J.E. Barralet, The effect of amorphous pyrophosphate on calcium phosphate cement resorption and bone generation, Biomaterials 34 (2013) 6631-6637.
[17] S.M. Naga, M. Awaad, H.F. El-Maghraby, A.M. El-Kady, Biological performance of calcium pyrophosphate-coated porous alumina scaffolds, Int. J. Appl. Ceram. Technol. 11 (2014) 1-11.

[18] S. Koo, B. König, S. Allegrini, M. Yoshimoto, M.J. Carbonari, F.F. Mitri-Luiz, Titanium implant osseointegration with calcium pyrophosphate in rabbits, J. Biomed. Mater. Res. B Appl. Biomater. 76 (2006) 373-380.

[19] J.H. Lee, B.S. Chang, U.O. Jeung, K.W. Park, M.S. Kim, C.K. Lee, The first clinical trial of beta-calcium pyrophosphate as a novel bone graft extender in instrumented posterolateral lumbar fusion, Clin. Orthop. Surg. 3 (2011) 238244.

[20] P. Gras, C. Rey, O. Marsan, S. Sarda, C. Combes, Synthesis and characterisation of hydrated calcium pyrophosphate phases of biological interest, Eur. J. Inorg. Chem. 34 (2013) 5886-5895.

[21] B.M. Fung, A.K. Khitrin, K. Ermolaev, An improved broadband decoupling sequence for liquid crystals and solids, J. Magn. Reson. 142 (2000) 97-101.

[22] P. Sepulveda, J.R. Jones, L.L. Hench, Characterization of melt-derived 45s5 and sol-gel-derived $58 S$ bioactive glasses, J. Biomed. Mater. Res. 58 (2001) 734740 .

[23] M. Mathew, H.L. Ammon, Crystal structure of decacalcim tetrapotassium hexakis (pyrophosphate) nonhydrate, J. Chem. Cryst. 25 (1995) 219-222.

[24] B.C. Cornilsen, Solid state vibrational spectra of calcium pyrophosphate dehydrate, J. Mol. Struct. 117 (1984) 1-9.

[25] P. Gras, A. Baker, C. Combes, C. Rey, S. Sarda, A.J. Wright, M.E. Smith, J.V. Hanna, C. Gervais, D. Laurencin, C. Bonhomme, From crystalline to amorphous calcium pyrophosphates: a solid state nuclear magnetic resonance perspective, Acta Biomater. 31 (2016) 348-357.

[26] W. Kolodziejski, Solid-state NMR studies of bone, Top. Curr. Chem. 246 (2005) 235-270.

[27] C. Slater, D. Laurencin, D.V. Burnell, M.E. Smith, L.M. Grover, J.A. Hriljac, A.J. Wright, Enhanced stability and local structure in biologically relevant amorphous materials containing pyrophosphate, J. Mater. Chem. 21 (2011) 18783-18791.

[28] R.K. Brow, Review: the structure of simple phosphate glasses, J. Non-Cryst. Sol. $263(2000) 1-28$

[29] D.S. Brauer, R.M. Wilson, T. Kasuga, Multicomponent phosphate invert glasses with improved processing, J. Non-Cryst. Sol. 358 (2012) 1720-1723.

[30] J. Kim, D.D. Arola, L. Gu, Y.K. Kim, S. Mai, Y. Liu, D.H. Pashley, R.R. Tay, Functional biomimetic analogs help remineralize apatite-depleted demineralized resin-infiltrated dentin via a bottom-up approach, Acta Biomater. 6 (2010) 2740-2750.

[31] L. Wang, G.H. Nancollas, Calcium orthophosphates: crystallization and dissolution, Chem. Rev. 108 (2008) 4628-4669.

[32] F. Nudelman, K. Pieterse, A. George, P.H.H. Bomans, H. Friedrich, L.J. Brylka, P.A. J. Hilbers, G. De With, N.A.J.M. Sommerdijk, The role of collagen in bone apatite formation in the presence of hydroxyapatite nucleation inhibitors, Nat. Mater. 9 (2010) 1004-1009.

[33] A.N. Lazarev, Vibrational Spectra and Structure of Silicates, Consultants Bureau, New York, 1972.

[34] C. Thouverey, G. Bechkoff, S. Pikula, R. Buchet, Inorganic pyrophosphate as a regulator of hydroxyapatite or calcium pyrophosphate dihydrate mineral deposition by matrix vesicles, Osteoarthritis Cartilage 17 (2009) 64-72.

[35] N. Eidelman, W.E. Brown, J.L. Meyer, J. Cryst. Growth 108 (1991) 385-393.

[36] H. Fleisch, S. Bisaz, Mechanism of calcification: inhibitory role of pyrophosphate, Nature 195 (1962) 901-903.

[37] C. Combes, C. Rey, Amorphous calcium phosphates: synthesis, properties and uses in biomaterials, Acta Biomater. 6 (2010) 3362-3378.

[38] P. Gras, Etude physico-chimique et structurale de pyrophosphates de calcium hydrates: application aux micro-calcifications associées à l'arthrose (Ph.D. thesis), Université de Toulouse, 2014. II-15.

[39] L. Montagne, G. Palavit, R. Delaval, ${ }^{31} \mathrm{P}$ NMR in $(100-\mathrm{x})\left(\mathrm{NaPO}_{3}\right)-\mathrm{xZnO}$ glasses, J. Non-Cryst. Sol. 215 (1997) 1-10. 